\section{IT-Gipfel 2012}

Spitzentreffen der Bundesregierung mit der IT-Wirtschaft und Wissenschaft: am 13. November 2012 findet in Essen der 7. Nationale IT-Gipfel in Anwesenheit der Bundeskanzlerin und des verantwortlichen Bundesministers für Wirtschaft und Technologie Dr. Rösler statt. Die Digitalisierung der Wirtschaft, Intelligente Netze und junge IKT-Unternehmen bilden die diesjährigen Schwerpunkte dieser zentralen Plattform für die Umsetzung der IKT-Strategie „Deutschland Digital 2015“ der Bundesregierung.

\section{Jahre GI-Regio- nalgruppe in Braun- schweig: 180 Gäste und jede Menge Zuversicht in eine gute Zukunft}

Die Zukunft hat die Menschen schon immer fasziniert - so auch die 180 Geburtstagsgäste, die das 25-jährige Bestehen der Braunschweiger Regionalgruppe der Gesellschaft für Informatik gefeiert haben. Die Festveranstaltung im Braunschweiger Altstadtrathaus am 7. Juni bot die besondere Gelegenheit, dem deutschen Trend- und Zukunftsforscher, Matthias Horx, zuzuhören und mit ihm zu diskutieren.

Horx zeigte in seinem Vortrag die großen Veränderungsfaktoren unserer Welt und konnte jede Menge

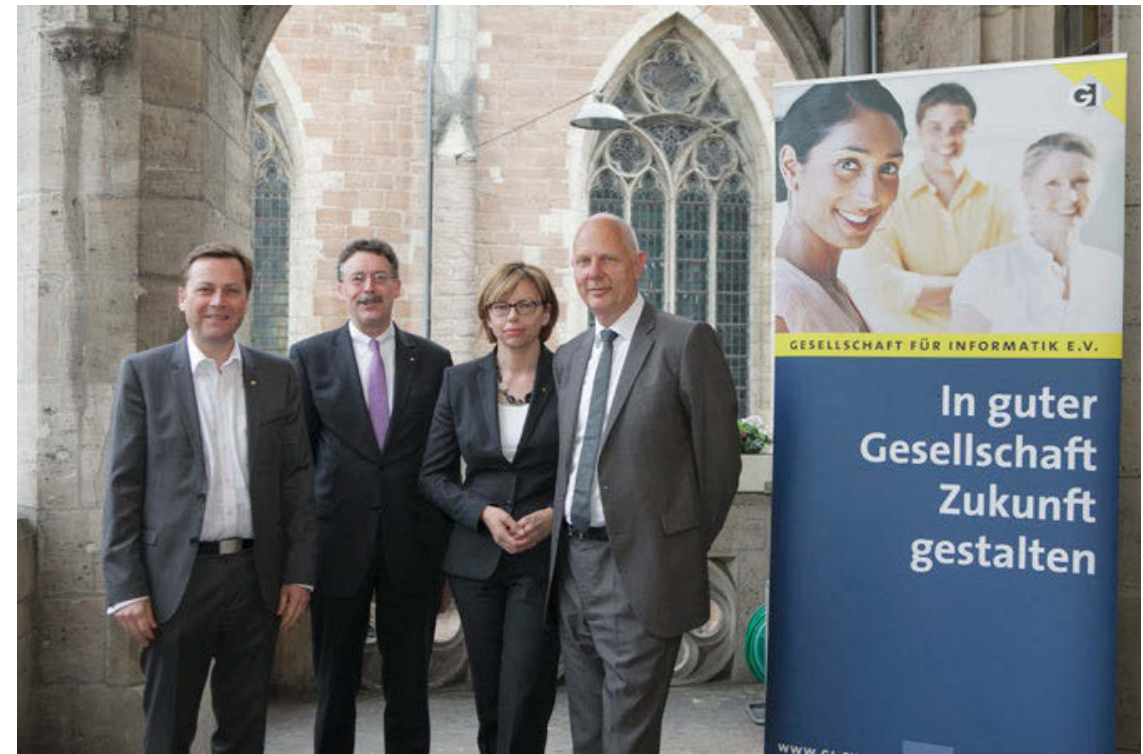

(Von links) Prof. Oliver Günther, Dr. Bernd Meier, Anja Schaar-Goldapp und Matthias Horx, Foto: Peter Sierig

Optimismus verbreiten, dass die Welt von morgen nicht schlechter, sondern besser wird. Horx' großes Thema, die Zukunft, ist auch der GI wichtig. „Die Informatik trägt eine hohe Verantwortung für die Zukunft. Sie in der Region Braunschweig zu gestalten, macht großen Spaß", sagte Regionalgruppen-Sprecherin Anja Schaar-Goldapp.

Für die Arbeit der Braunschweiger Regionalgruppe hatte Prof. Oliver Günther „nur Lob übrig“. Für den GI-Präsidenten und Präsidenten der Universität Potsdam ist es ,,sehr wichtig, funktionierende Regionalgruppen zu haben - und die Braunschweiger Gruppe ist dafür ein leuchtendes Beispiel“. Dass sie es seit 25 Jahren vorbildlich schaffe, sich gemeinsam mit Hochschulen, Industrie und Verwaltung auszutauschen, Veranstaltungen $\mathrm{zu}$ organisieren und den Nachwuchs zu fördern - „dafür meinen herzlichen Glückwunsch“. Er gratulierte allen Mitgliedern des Leitungsgremiums der Regionalgruppe Braunschweig. Neben der Sprecherin Anja Schaar-Goldapp sind hier Prof. Ina Schiering, Prof. Hartmut Helmke, André Richter und Prof. Susanne Steiner seit vielen Jahren aktiv.

Auch Dr. Bernd Meier, Hauptgeschäftsführer der IHK Braunschweig, reihte sich in die Gratulanten ein - mit einer interessanten Zeitreise zurück zu den Orten Braunschweiger Highlights, die ohne die Informatik nicht möglich gewesen wären: vom Braunschweiger Commodore-Werk, in dem der C64 gebaut wurde, bis hin zum Flughafen Braunschweig, Schauplatz der ersten vollautomatischen Landung eines Flugzeugs mit GPS-Unterstützung. Dr. Meier ging mit eindrucksvollen

DOI 10.1007/s00287-012-0645-0

Die Fortsetzung der Mitteilungen folgt auf Seite 381. 